\title{
Periodic Breathing Cycle Duration in Preterm Infants
}

\author{
S. F. GLOTZBACH, P. A. TANSEY, R. B. BALDWIN, AND R. L. ARIAGNO \\ Department of Pediatrics, Division of Neonatology, Stanford University School of Medicine, Stanford, CA 94305
}

\begin{abstract}
Periodic breathing cycle duration (PCD), the time interval from the beginning of one respiratory pause to the beginning of the next pause within an episode of periodic breathing (PB), was measured by examination of 24-h impedance pneumograms in 51 preterm infants. Calculations of the $\mathrm{SD}$ of $\mathrm{PCD}$ within a given $\mathrm{PB}$ episode $(\sim 3$ s) and comparison of $P C D$ values between two $P B$ episodes in each infant $(r=0.68)$ revealed considerable variability in PCD. This variability was not related to the number of cycles in the PB episode or to the amount of $\mathrm{PB}$ in the recording. Contrary to the decrease in PCD from $15.0 \mathrm{~s}$ at $1 \mathrm{wk}$ to $12.4 \mathrm{~s}$ at $12 \mathrm{wk}$ in term infants reported previously, PCD did not vary as a function of postconceptional, gestational, or postnatal age in our preterm population. PCD has limited value as an indicator of chemoreceptor maturation in the preterm infant, and most likely reflects transient adjustments in respiratory system control. (Pediatr Res 25:258-261, 1989)
\end{abstract}

Abbreviations

PB, periodic breathing

PCD, periodic breathing cycle duration

GA, gestational age

PNA, postnatal age

$\mathrm{CA}$, postconceptional age

QT, quiet time

SIDS, sudden infant death syndrome

$\mathrm{PB}$, a respiratory pattern consisting of alternating respiratory pauses and breaths, has been studied extensively in infants during the last decade. PB comprises $<2 \%$ of the respiratory pattern in most normal infants during the first months of life $(1-3)$, and occurs more frequently and in higher amounts in preterm infants (4-8). PB may therefore reflect an immaturity of developing respiratory control system elements which does not normally indicate any abnormalities or pathology; however, elevated amounts of PB have been reported in some infants "near-miss" for SIDS and in some SIDS victims (9-13).

Although most studies of PB in infants have been limited to observations on the incidence or amount of PB in normal and high-risk groups, relatively few investigations have focused on the mechanisms underlying PB. Recently, Barrington et al. (14) described a decrease in PCD in term infants during the-first 3 mo of life. PCD was-calculated for $2-10$ cycles/PB episode and was defined as the time interval between the initial breath of one breathing/respiratory pause cycle and the initial breath of the

Received May 23, 1988; accepted October 27, 1988

Correspondence and reprint requests R. L. Ariagno, M.D., Department of Pediatrics, Stanford University School of Medicine, Stanford, CA 94305.

Supported in part by NIH Grant RR-81, The National Center for the Prevention of SIDS, Healthdyne Inc., and the Cebrian Research Fund. next. PCD progressively decreased from $15.0 \mathrm{~s}$ at $1 \mathrm{wk}$ to $12.4 \mathrm{~s}$ at $12 \mathrm{wk}$, and these authors proposed that PCD may provide a noninvasive index of respiratory system chemoreceptor maturation in the infant during development.

In the present study, we measured PCD during two episodes of $\mathrm{PB}$ in 51 preterm infants. Information about PCD in preterm infants is of interest for several reasons. First, the observations of Barrington et al. (14) regarding PCD and age can be extended to earlier GA and CA groups. Second, the percentage of PB and duration of the longest episode of $\mathrm{PB}$ in preterm infants are an order of magnitude higher than comparable values from term infants (8), and therefore data on PCD in preterm infants would allow a more detailed examination of the characteristics and variability of $P C D$ in this age group. Finally, if $P C D$ values reflect the developmental status of the respiratory control system, measurement of PCD in preterm infants, who are at higher epidemiologic risk for SIDS (15), may be useful in determining respiratory system pathology in some infants.

\section{METHODS}

Prior to discharge from the Stanford newborn nurseries, 51 preterm infants were studied. After written consent was granted by the parents, 24-h cardiorespiratory pneumograms were obtained at the infant's bedside in the intermediate or intensive care nurseries. Changes in arousal state were not monitored in these studies. Two-channel thoracic impedance pneumograms were recorded with a Healthdyne Infant Monitor (Healthdyne Inc., Marietta, GA) (model 16900) at a paper speed of $25 \mathrm{~mm} /$ min. Infants were eligible for this study if they were within 2 wk of expected discharge home, had normal body temperatures while clothed in an open crib, and were asymptomatic for apnea and bradycardia. Premature infants at Stanford are usually considered ready for discharge when they are feeding well by bottle or breast and gaining wt consistently, which frequently coincides with a CA of 36-37 wk and body wt approaching $2000 \mathrm{~g}$. Infants who were on theophylline, who had chronic pulmonary disease requiring diuretics or supplemental oxygen treatment, or who had intracranial hemorrhage (grades 3 or 4 ) were excluded.

The infants in this study were a subset of 66 preterm infants in which characteristics of $\mathrm{PB}$ were previously reported (8). The characteristics of this preterm population are summarized in Table 1. PB was defined as an episode of three or more respiratory pauses of $\geq 3 \mathrm{~s}$ duration with intervening periods of respiration of $\leq 20 \mathrm{~s}$. PCD was defined in this study as the time interval from the beginning of one respiratory pause to the beginning of the next pause (Fig. 1). To optimize our ability to observe variability in $\mathrm{PCD}$, we examined the records of infants where the longest episode of PB exceeded 2 min. Two PB episodes were chosen from each of these 51 infants: the longest episode (E1) and another, arbitrarily chosen episode (E2). All of the PCD intervals in each PB episode were measured, and the mean PCD $( \pm \mathrm{SD})$ was calculated. The correlation between mean PCD E1 and mean PCD E2 for all infants was tested by linear regression 
to assess the variability between the two different episodes. An overall periodic breathing cycle duration was derived for each infant from the average of the two mean PCD $\left(\left[\overline{\mathrm{PCD}}_{\mathrm{E} 1}+\overline{\mathrm{PCD}}_{\mathrm{E} 2}\right]\right.$ 12 ), and the nonparametric Kruskal-Wallis test was used to determine whether the overall PCD varied between different $C A$ groups. Multiple regression analysis was used to examine possible relationships between GA, PNA, and PCD. Results were considered significant at $p<0.05$.

\section{RESULTS}

Variability in PCD. The analysis of over $2600 \mathrm{~PB}$ cycles revealed that $P C D$ values varied considerably both within a given PB episode and between E1 and E2 of each infant (Table 1). The variability in $\mathrm{PCD}$ within a given $\mathrm{PB}$ episode was analyzed by calculating the mean of the SD of E1 and E2 for all the infants. These SD means were 3.2 and $2.8 \mathrm{~s}$, respectively, which are more than the 2.6-s difference in PCD between 1 and $12 \mathrm{wk}$ in term infants (14).

If PCD is primarily related to the age of an infant, we would expect no difference in the mean PCD values of $E 1$ and $E 2$. In our data, the relationship between E1 and E2 showed a significant linear trend $(r=0.68, p<0.01)$; however, 24/51 (47\%) of the values fell outside of the $95 \%$ confidence limits for the true mean of $Y$ (Fig. 2). The difference between the $\overline{\mathrm{PCD}}_{\mathrm{E} 1}$ and the $\overline{\mathrm{PCD}}_{\mathrm{E} 2}$ for each infant varied from 0 to $6.9 \mathrm{~s}$ (mean $1.5 \pm 1.5 \mathrm{~s}$ ).

The variability in PCD was not a function of either the number of cycles in the PB episode $(r=0.22, p>0.05)$, the amount of $\mathrm{PB}$ in the recording (\% $\mathrm{PB} / \mathrm{QT}$ versus $\mathrm{PCD}, r=0.12, p>0.05)$, or the duration of $\mathrm{E} 1(r=0.11, p>0.05)$.

Table 1. Study characteristics of preterm infants $(n=51)$

\begin{tabular}{lc}
\hline \multicolumn{1}{c}{ Parameter } & Mean \pm SD (range) \\
\hline GA (wk) & $32.4 \pm 2.4(26-36)$ \\
Chronological age (wk) & $4.6 \pm 2.9(1-11)$ \\
CA (wk) & $37.0 \pm 1.9(33-41)$ \\
Birth wt (kg) & $1.59 \pm 0.43(0.71-2.55)$ \\
Study wt (kg) & $2.12 \pm 0.44(1.44-3.10)$ \\
Total recording time (min) & $1350 \pm 191(639-1641)$ \\
\% PB/QT* & $14.9 \pm 11.7(1.14-53.21)$ \\
Duration of E1 (min) & $9.0 \pm 7.9(2.1-34.4)$ \\
No. of PB cycles (E1) & $34.8 \pm 32.0(6-151)$ \\
No. of PB cycles (E2) & $17.4 \pm 14.2(4-80)$ \\
Overall PCD (sec) & $15.2 \pm 2.4(10.3-22.7)$ \\
Gender (male:female) & $30: 21$ \\
\hline
\end{tabular}

* QT was estimated by excluding periods where artifact or sustained elevations in heart rate dominated that portion of the record.
Relationship between age and $P C D$. The influence of $\mathrm{CA}, \mathrm{GA}$, and PNA on PCD is depicted in Figure 3. There were no significant differences in PCD between different CA groups ( $p=$ 0.408 ). Moreover, multiple regression analysis showed that PCD was not related to GA or PNA $(p>0.13)$.

\section{DISCUSSION}

Previous studies of $\mathrm{PB}$ in preterm and term infants have largely been confined to descriptions of the number of episodes, episode lengths, and the percentage of $\mathrm{PB}$ in a recording $(2,3,8)$. However, the mechanisms which determine the timing, generation, and characteristics of PB episodes are poorly understood. Several groups have provided models of the temporal organiza-

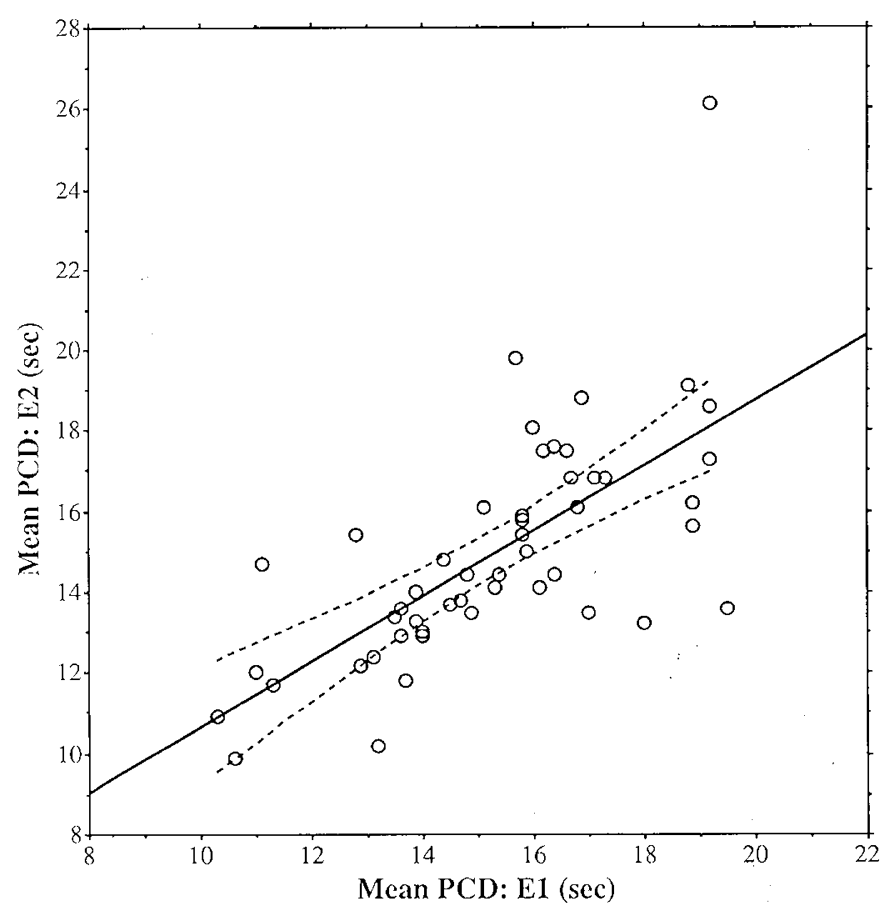

Fig. 2. Linear regression of the $\mathrm{PCD}$ of $\mathrm{PB}$ episode $\mathrm{E} 1$ versus $\mathrm{E} 2$ for all 51 preterm infants. The relationship between $\mathrm{E} 1$ and $\mathrm{E} 2$ is described by $y=0.81 x+2.59 ;(\mathrm{r}=0.68, p<0.01)$. Nearly half of the values lie outside of the $95 \%$ confidence limits for the true mean of $Y$ (dotted lines).

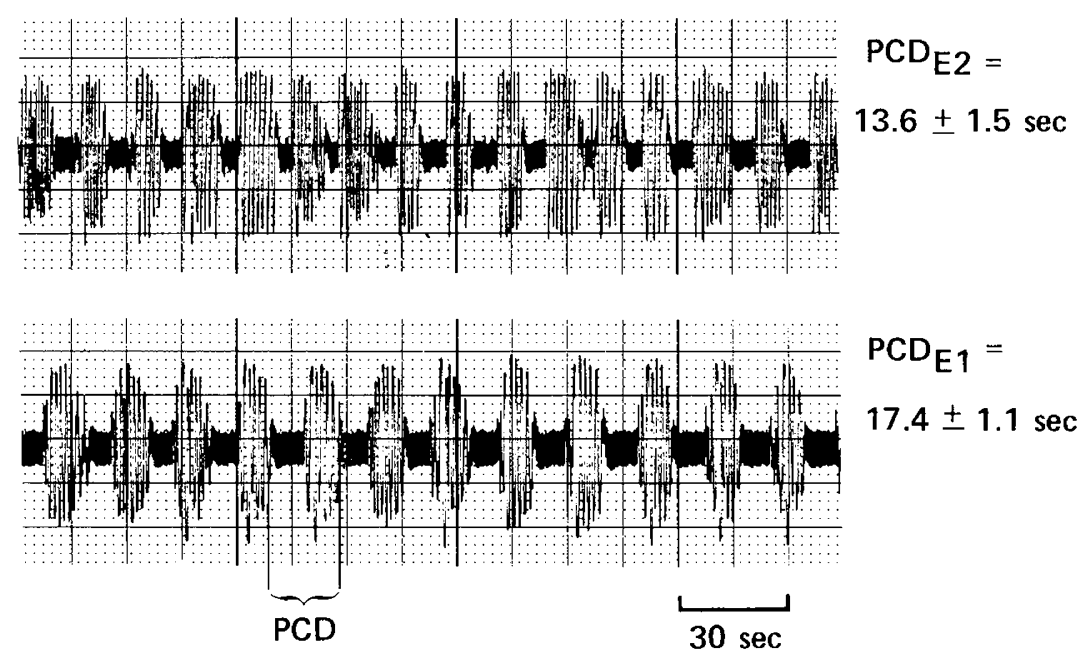

Fig. 1. An example of two PB segments (from E1 and E2) obtained from one infant. PCD was measured between the beginnings of successive respiratory pauses. The difference in mean periodic breathing cycle duration between these two episodes, which were separated by $9.3 \mathrm{~h}$, was $3.8 \mathrm{~s}$. 

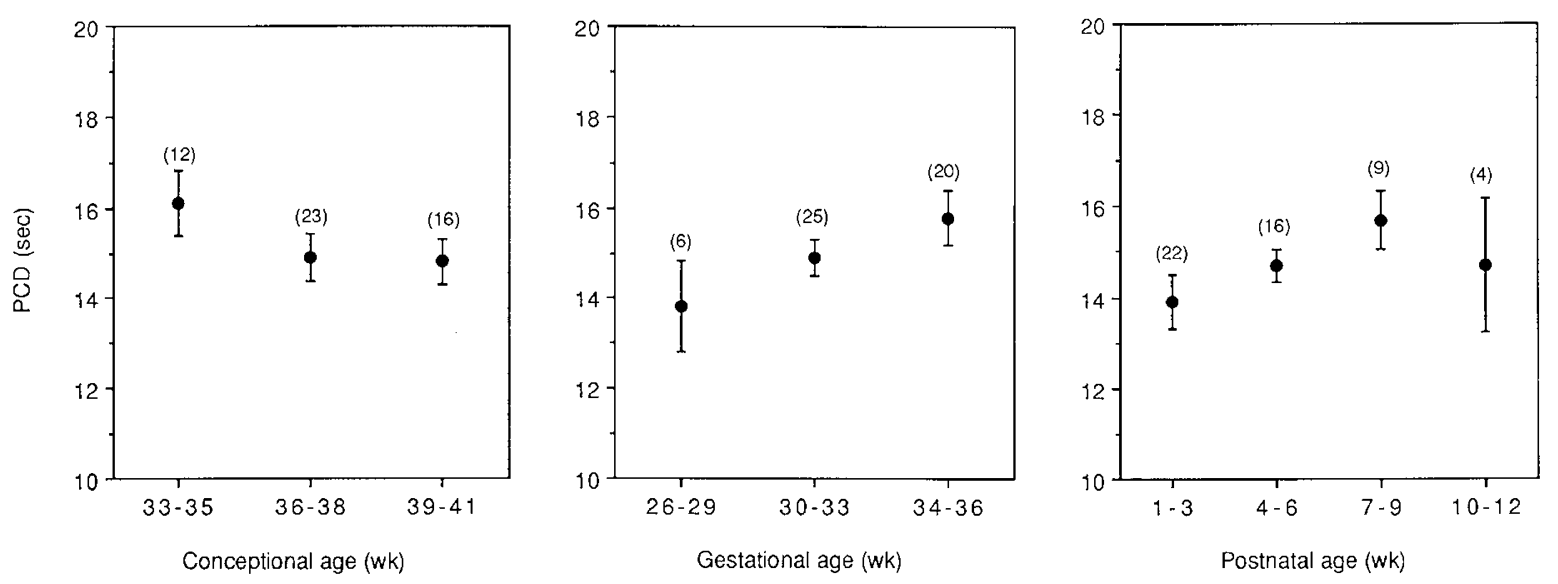

Fig. 3. The mean ( \pm SEM) PCD as a function of postconceptional, gestational, and postnatal age reveals no difference in periodic breathing cycle duration with age group $(p>0.13)$. Pneumograms were obtained near the time of discharge from the nursery; therefore, infants at earlier GA were studied at relatively later PNA, and infants approaching term were studied at relatively earlier PNA. The numbers in parentheses refer to the number of infants in each group.

tion and cyclicity of PB and apnea (16-18), but little actual data are available on the infrastructure of infant PB episodes. Barrington et al. (14) recently studied the interval between respiratory cycles within an PB episode in term infants, and found that cycle duration progressively decreased over the first 3 mo of life. As physiologic (19) and histochemical (20) studies also support the concept of decreased respiratory chemoreceptor delay time with postnatal development, Barrington et al. (14) suggested that PCD values could provide a noninvasive index of both normal and abnormal respiratory chemoreceptor maturation in the infant. For example, the elevated dopamine levels found in the carotid bodies of some SIDS victims may reflect abnormal maturation of peripheral chemoreceptor activity $(21,22)$, and it is possible that PCD values could provide a novel tool for determining respiratory system pathology where examination of other PB parameters have failed to differentiate consistently infants at risk for SIDS from normal infants (13, 23-25).

In contrast to the results of Barrington et al. (14), there was no correlation between PCD values and age in preterm infants in this study. Furthermore, substantial variability in PCD exists both within a given episode of $\mathrm{PB}$ and between two different episodes from each infant. There are several possible explanations for the differences in our data and the results of Barrington et al. (14). First, the PB parameters studied most often (\%PB/ QT, number of episodes PB/100 min QT, mean length of PB, and duration of the longest episode of $\mathrm{PB}$ ) are all significantly higher in preterm infants than in normal term infants (8). We thus had the opportunity to measure and compare PCD in two relatively long $\mathrm{PB}$ episodes from each infant, and we measured all cycles in each of these two episodes (mean 34.8 and 17.4 cycles for $\mathrm{E} 1$ and $\mathrm{E} 2$, respectively). As the mean duration of $\mathrm{PB}$ episodes is approximately $45 \mathrm{~s}$ in term infants (2), Barrington et al. (14) had access to relatively few PB cycles in each PB episode, and it was not stated if all the cycles within an episode were chosen for analysis.

Second, PB occurs during both quiet sleep and active sleep in preterm infants; however, it is largely confined to active sleep in term infants $(7,14,26-28)$. Although Barrington et al. (14) reported that $P C D$ was not significantly influenced by sleep state in term infants, the higher amount of PB occurring in quiet sleep coupled with longer PB episodes in preterm infants compared to term infants suggests that sleep state could influence PCD variability, especially in light of the sleep state-dependent changes in respiratory control system characteristics which occur in both adults and infants (29).

In summary, the age-related decline in PCD seen in term infants (14) was not found in the preterm infants in this study. Moreover, the high variability of preterm PCD values appears to limit the utility of PCD in predicting dysfunction of chemoreceptor control or postneonatal morbidity. Future studies focusing on the relationship between PCD, sleep state, and arterial oxygen tension will provide further insight into the mechanisms governing PCD variability in preterm infants.

Acknowledgment. We thank Dr. Byron Brown for his assistance with statistical analysis of the data.

\section{REFERENCES}

1. Richards JM, Alexander JR, Shinebourne EA, de Swiet M, Wilson AJ, Southall DP 1984 Sequential 22-hour profiles of breathing patterns and heart rate in 110 full-term infants during their first 6 months of life. Pediatrics 74:763777

2. Kelly DH, Stellwagen LM, Kaitz E, Shannon DC 1985 Apnea and periodic breathing in normal full-term infants during the first twelve months. Pediatr Pulmonol 1:215-219

3. Hunt CE, Brouillette RT, Hanson D, David RJ, Stein IM, Weissbluth M 1985 Home pneumograms in normal infants. J Pediatr 106:551-555

4. Parmelee AH, Stern E, Harris MA 1972 Maturation of respiration in prematures and young infants. Neuropediatrie 3:294-304

5. Fenner A, Schalk U, Hoenicke H, Wendenburg A, Roehling T 1973 Periodic breathing in premature and neonatal babies: incidence, breathing pattern, respiratory gas tensions, responses to changes in the composition of ambient air. Pediatr Res 7:174-183

6. Curzi-Dascalova L, Christova-Gueorguieva E 1983 Respiratory pauses in normal prematurely born infants. A comparison with full-term newborns. Biol Neonate 44:325-332

7. Albani M, Bentele KHP, Budde C, Schulte FJ 1985 Infant sleep apnea profile: preterm $v s$. term infants. Eur J Pediatr 143:261-268

8. Glotzbach SF, Baldwin RB, Lederer NE, Tansey PA, Ariagno RL Incidence and characteristics of periodic breathing in preterm infants. Pediatrics (in press)

9. Kelly DH, Shannon DC 1979 Periodic breathing in infants with near-miss sudden infant death syndrome. Pediatrics 63:355-360

10. Hunt CE, Brouillette RT, Hanson D 1983 Theophylline improves pneumogram abnormalities in infants at risk for sudden infant death syndrome. $J$ Pediatr 103:969-974

11. Kahn A, Blum D, Montauk L 1986 Polysomnographic studies and home monitoring of siblings of SIDS victims and of infants with no family history of sudden infant death. Eur J Pediatr 145:351-356

12. Southall DP, Richards JM, Stebbens V, Wilson AJ, Taylor V, Alexander JR 1986 Cardiorespiratory function in 16 full-term infants with sudden infant death syndrome. Pediatrics 78:787-796

13. Kelly DH, Golub H, Carley D, Shannon DC 1986 Pneumograms in infants who subsequently died of sudden infant death syndrome. J Pediatr 109:249254

14. Barrington KJ, Finer NN, Wilkinson MH 1987 Progressive shortening of the periodic breathing cycle duration in normal infants. Pediatr Res 21:247-251

15. Black L, David RJ, Brouillette RT, Hunt CE 1986 Effects of birth weight and ethnicity on incidence of sudden infant death syndrome. J Pediatr 108:209214

16. Waggener TB, Frantz ID, Stark AR, Kronauer RE 1982 Oscillatory breathing patterns leading to apneic spells in infants. J Appl Physiol 52:1288-1295.

17. Khoo MCK, Kronauer RE, Strohl KP, Slutsky AS 1982 Factors inducing periodic breathing in humans: a general model. J Appl Physiol 53:644-659 
18. Chapman KR, Bruce EN, Gothe B, Cherniack NS 1988 Possible mechanisms of periodic breathing during sleep. J Appl Physiol 1000-1008

19. Bureau MA, Lamarche J, Foulon P, Dalle D 1985 Postnatal maturation of respiration in intact and carotid body denervated lambs. J Appl Physiol 59:869-874

20. Hervonen A, Kanerva L, Korkala O, Paranen S, 1972 Effects of hypoxia and glucocorticoids on the histochemically demonstrable catecholamines of the newborn rat carotid body. Acta Physiol Scand 86:109-114

21. Mayock DE, Standaert TA, Guthrie RD, Woodrum DE 1983 Dopamine and carotid body function in the newborn lamb. J Appl Physiol 54:814-820

22. Perrin DG, Cutz E, Becker Le, Bryan AC, Madapallimatum A, Sole MJ 1984 Sudden infant death syndrome: increased carotid body dopamine and noradrenaline content. Lancet 2:535-537

23. Steinschneider A, Weinstein SL, Diamond E 1982 The sudden infant death syndrome and apnea/obstruction during neonatal sleep and feeding. Pediatrics $70: 858-863$

24. Flores-Guevara R, Sternberg B, Peirano P, Guidasci S, Durupt N, Monod N 1986 Respiratory pauses and periodic breathing assessed by cardio-pneumography in normal infants and in SIDS siblings. Neuropediatrics 17:59-
62

25. Gordon D, Southall DP, Kelly DH, Wilson A, Akselrod S, Richards J, Kene B, Kenet R, Cohen RJ, Shannon DC 1986 Analysis of heart rate and respiratory patterns in sudden infant death syndrome victims and control infants. Pediatr Res 20:680-684

26. Hoppenbrouwers T, Hodgman JE, Harper RM, Hofmann E, McGinty DJ 1977 Polygraphic studies of normal infants during the first six months of life: III: incidence of apnea and periodic breathing. Pediatrics 60:418-425

27. Curzi-Dascalova L, Christova-Gueorguieva L, Lebrun F, Firtion G 1984 Respiratory pauses in very low risk prematurely born infants reaching normal term. A comparison to full-term newborns. Neuropediatrics 15:13-17

28. Bentele KHP, Albani M, Budde C, Schulte FJ 1985 Sleep apnoea profile in preterm infants recovering from respiratory distress syndrome. Arch Dis Child 60:547-554

29. Phillipson EA, Bowes G 1986 Control of breathing during sleep. In: Cherniack NS, Widdicombe JG (eds) Handbook of Physiology. Section 3: The Respiratory System. American Physiological Society, Bethesda, Maryland, pp 649689 